\title{
Mycobiota and AFM1 levels in food supplements for infants and seniors
}

\author{
Beatriz Clarissa dos Santos Ferreira e Pereira', Victor Moebus Farias ${ }^{1}$, Luiz Antonio Moura Keller², Robson Maia Fanco ${ }^{2}$
}

\begin{abstract}
This study aimed to show the presence of fungi in powder supplements for infants and for seniors, comparing counts among them as well as aflatoxin M1 levels. The overall average of fungal count and variety was high. Ten samples (approximately $11.6 \%$ ) were above the European Union limits $(0.05 \mu \mathrm{g} / \mathrm{kg})$ for aflatoxin M1. One sample was above United States limits $(0.5 \mu \mathrm{g} / \mathrm{kg})$. Such presence highlights the importance of good manufacturing practices and storage conditions, by both the industry and the consumers. It also can be considered a potential health risk due the inherent fragility of the target consumers. More studies are suggested to better understand fungi growth and mycotoxin production in such matrix.
\end{abstract}

Keywords: Food supplements, fungi count, aflatoxin M1, infants, seniors.

\section{Introduction}

Aflatoxins are metabolites produced by the fungi genus Aspergillus. They are commonly associated with crops, compromising livestock and food production worldwide. Animal products can also be compromised, such is the case of Aflatoxin M1, found in milk (MARCHESE, 2018; WHO, 2018).

There are no standards for fungi counts, be it on infant formulas or supplements for seniors which reinforce the need to assert the risk the consumer is exposed, unify the regulations available as well as establish new ones.

\section{Methodology}

A total of 18 infant formulas (IN) were obtained from the local hospital. For supplements for seniors (SE), all 64 samples were purchased from drugstores. The cans selected were in proper conditions and within the expiration date, with all samples collected in triplicate. Analyses were performed immediately at the arrival of the sample with subsequent storage $\left(-5^{\circ} \mathrm{C}\right)$.

Fungi counts were made using dichloran rose bengal chloramphenicol agar (DRBC) (ABARCA et al., 1994) for estimation of total culturable micoflora and dichloran $18 \%$ glycerol agar (DG18) (PITT \& HOCKING, 1997) for xerophilic fungi. Nonspecific filamentous genus, Aspergillus sp., Pencillium sp. and Fusarium sp. species were identified, respectively, according to Samson et al. (2004), Klich (2002), Pitt; Hocking (1997) and Nelson et al. (1983).

Aflatoxin extraction method was based on modified QuEChERS, following methodology described in by the Association of Official Analytical Chemists International (2007). Screening was performed using AFM1 commercial kits (Aflatest $囚$, Vicam, Watertown, MA, USA), with quantification and analysis done with VICAM® Series4EX fluorimeter (Watertown, MA, USA) and HPLC quantification. The limits of detection (LOD) and quantification (LOQ) were found by the variation of concentrations of the standard solution and subjected to extraction and quantification until the lowest detectable concentration (LOD) and the lowest quantifiable concentration (LOQ) under suitable conditions of repeatability
( $n=5, \mathrm{RSD}<15 \%$ ). The detection and quantification limits were $0.013 \mu \mathrm{g} / \mathrm{kg}$ and $0.055 \mu \mathrm{g} / \mathrm{kg}$, respectively.

\section{Results and Discussion}

The different CV obtained in fungi counts show heterogeneity between groups of data obtained. Filamentous fungi counts, made in DRBC agar, varied from $1.00 \times 10^{2}$ to $9.00 \times 10^{3} \mathrm{CFU} / \mathrm{g}$ in SE samples and from $1.00 \times 10$ to $5.00 \times 10^{3} \mathrm{CFU} / \mathrm{g}$ in IN samples, with a $\mathrm{CV}$ of 1.43 and 1.36 , respectively. Both can be considered homogeneous due to the low $\mathrm{CV}$.

The DG18 agar, used for xerophilic fungi counts, had a higher coefficient of variation in SE (2.12), indicating a high dispersion of data. There was also a big difference between minimum and maximum scores $\left(1.00 \times 10^{2}\right.$ to $2.00 \times 10^{4} \mathrm{CFU} / \mathrm{g}$ respectively). Such high levels were not mirrored by IN, which varied from 1.00 $x 10^{2}$ to $7.20 \times 10^{4} \mathrm{CFU} / \mathrm{g}$, with a CV of 0.53 .

Fungi counts are described on more detail on table 1.

Table 1: Fungi counts in DRBC and DG18

\begin{tabular}{ccc}
\hline Brand & DRBC (CFU/gram) & DG 18 (CFU/gram) \\
\hline IN1 & $1.28 \times 10^{3 a}$ & $5.37 \times 10^{3 a}$ \\
IN2 & $1.05 \times 10^{2 a}$ & $1.80 \times 10^{4 a}$ \\
IN3 & $2.85 \times 10^{2 a}$ & $1.01 \times 10^{3 a}$ \\
IN4 & $7.50 \times 10^{2 a}$ & $1.10 \times 10^{3 a}$ \\
IN5 & $4.10 \times 10^{2 a}$ & $7.20 \times 10^{4 a}$ \\
IN6 & $4.20 \times 10^{2 a}$ & $1.00 \times 10^{3 a}$ \\
IN7 & $4.20 \times 10^{2 a}$ & $1.00 \times 10^{2 a}$ \\
\hline Average & $5.24 \times 10^{2}$ & $1.4 \times 10^{4}$ \\
\hline SE1 & $2.99 \times 10^{3 a}$ & $1.25 \times 10^{3 a}$ \\
SE2 & $1.40 \times 10^{3 b}$ & $3.30 \times 10^{3 a}$ \\
SE3 & $1.30 \times 10^{3 b}$ & $3.26 \times 10^{3 a}$ \\
SE4 & $2.99 \times 10^{2 b}$ & $4.35 \times 10^{2 a}$ \\
\hline Average & $1.50 \times 10^{3}$ & $2.06 \times 10^{3}$ \\
\hline
\end{tabular}

$\mathrm{a}, \mathrm{b}$ Means with the same letter in column are equivalent in accordance with ANOVA associated with Tukey and Pearson correlation $(P \leq 0.005)$.

c Technical Limit of Detection: $\leq 1.0 \times 10^{2} \mathrm{CFU} / \mathrm{gram}$.

${ }^{1} \mathrm{PhD}$ student of Veterinary Medicine post-graduation course Higiene Veterinária e Tecnologia de Produtos de Origem Animal, University Federal Fluminense (UFF). Rua Vital Brazil Filho 64, Niterói, Rio de Janeiro, Brasil. 24230-340. E-mail: beatrizclarissapereira@gmail.com

${ }^{2}$ Professor of Veterinary Medicine post-graduation course Higiene Veterinária e Tecnologia e Produtos de Origem Animal, University Federal Fluminense (UFF). 
In addition to the high counts, a wide variety of fungi genus was isolated. Predominant species included $A$. flavus, $A$. fumigatus, $A$. ochraceus, $A$. oryzae, $A$. parasiticus and $A$. niger, $P$. citrinum and $P$. citronigrum, and $F$. verticillioides, F.solani and F. chlamydosporum.

For AFM1 detection the Limit of Detection (LOD) used was $\leq 0.013 \mu \mathrm{g} / \mathrm{kg}$ and the Limit for Quantification (LOQ) was 0.055 $\mu \mathrm{g} / \mathrm{kg}$, with most AFM1 levels below one or both limits. There were also few samples above the maximum levels of AFM1 in milk and milk products determined by the European Union (EU) $(0.05 \mu \mathrm{g} / \mathrm{kg})$, United States (US) and Brazil $(0.5 \mu \mathrm{g} / \mathrm{kg}$ both) (EUROPEAN COMISSION, 2005; FOOD AND AGRICULTURE ORGANIZATION, 2004; BRAZIL, 2011).

For infant formulas, one sample was above EU limits $(0.39 \mu \mathrm{g} /$ $\mathrm{kg}$ ) and another above all limits considered in this study (0.59 $\mu \mathrm{g} / \mathrm{kg}$ ). Supplements for seniors had nine samples considered above the EU limits but no other limits were surpassed.

There are no official limits for fungi counts in infant formulas or senior supplements, therefore it was used the limit proposed by the United States Pharmacopeia (USP, 2015) of $10 \mathrm{CFU/g}$ for

\section{Bibliography}

ABARCA, M. L.; BRAGULAT, M. R.; CASTELLA, G.; CABAÑES, F. J. Ochratoxin A production by strains of Aspergillus niger var. niger. Applied Environmental Microbiology, v. 60, n. 7, p. 26502652, 1994. Available at: <https://www.ncbi.nlm.nih.gov/pmc/ articles/PMC201698/>. Last access: 20/10/2019.

ASSOCIATION OF OFFICIAL ANALYTICAL CHEMISTS INTERNATIONAL Official Methods of Analysis of The Association of Official Analytical Chemists. 19th ed., AOAC International, Maryland, 2007.

BRAZIL. Agência Nacional de Vigilância Sanitária - ANVISA. Resolução da diretoria colegiada- RDC n7, de 18 de fevereiro de 2011. Dispõe sobre limites máximos tolerados (LMT) para micotoxinas em alimentos. 2011 In: Diário Oficial [da] República Federativa do Brasil, Brasília. Available at: <http://bvsms.saude. gov.br/bvs/saudelegis/anvisa/2011/res0007_18_02_2011_rep. html>. Last access: 14/04/2016.

EUROPEAN COMMISSION. Commission Regulation No 2073/2005 of 15 November 2005 on microbiological criteria for foodstuffs. Official Journal of the European Union, L. 50, p. 1-26, November, 2005.

FOOD AND AGRICULTURE ORGANIZATION. Worldwide regulations for mycotoxins in food and feed in 2003. FAO Food and Nutrition paper 81: Rome. 2004.

WORLD HEALTH ORGANIZATION. Aflatoxins. Food Safety Digest. Department of Food Safety and Zoonosis, 2018. Available at: <https://www.who.int/foodsafety/FSDigest_ Aflatoxins_EN.pdf>. Last access:14/02/2021. food supplements in general. By that standard most samples were above the limit and should not be considered acceptable for consumption. The high counts, as well as the variety of fungi found, are justified by the diversity of ingredients of the matrix, each subject to contamination during production, storage, and transportation processes.

Perhaps more worrying than fungi counts is the toxigenic potential of some strains. Sibaja et al. (2019) found AFM1 in all milk powder samples of their study, half above EU established limits, proving not only the presence of AFM1 but the possibility of it to remain even after manufacture. While this study had fewer samples above the same limit (around 13.4\%), it can indicate a potential risk for the consumer.

\section{Conclusion}

There are ingrained risks for both infants and seniors. The presence of fungi growth and AFM1 production bring to light concerns for storage conditions, be it industrial or domestic. More studies are suggested to better understand and quantify the risks, preserving the health of infants and seniors.

$\mathrm{KLICH}, \mathrm{M}$. A. Identification of common Aspergillus species. Centraalbureau voor schimmelcultures: Netherlands, 2002.

MARCHESE, S., POLO, A., ARIANO, A., VELOTTO, S., COSTANTINI, S., SEVERINO, L. Aflatoxin B1 and M1: Biological Properties and Their Involvement in Cancer Development Toxins, v. 10, n. 6, p. 214, 2018. Available at: < https://www.mdpi. com/2072-6651/10/6/214/htm>. Last access: 14/02/2021.

NELSON, P. E., TOUSSOUN, T. A., MARASAS, W. F. O. Fusarium species: an illustrated manual for identification. USA: The Pennsylvania State University Press, 1983.

PITT, J. L., HOCKING, A. D. Fungi and food Spoilage. 2 ed., New York: Springer Science, 1997.

SAMSON, R. A., HOEKSTRA, E. S., FRISVAD, J.C. Introduction to food-and airborne fungi, 7 ed. Netherlands: Centraalbureau Voor Schimmelcultures, Institute of the Royal Netherlands Academy of Arts and Sciences, 2004.

SIBAJA, K. V. M., GONÇALVEZ, K. D. M., GARCIA, S. O., FELTRIN, A. C. P. Aflatoxin $\mathrm{M}_{1}$ and $\mathrm{B}_{1}$ in Colombian milk powder and estimated risk exposure. Food Additives and Contaminants Part B Surveill, v. 12, n. 2, p. 97-104, 2019. Available at: < https:// pubmed.ncbi.nlm.nih.gov/30700225/>. Last access: 08/12/2019.

UNITED STATE PHARMACOPEIA. Microbiological Enumeration Tests - Nutritional and Dietary Supplements <2021>. United Stated Pharmacopeial Convention: Maryland, 2015. 